\title{
Parvovirus B19 seroconversion in a cohort of human immunodeficiency virus-infected patients
}

\author{
Kátia Martins Lopes de Azevedo ${ }^{1 /+}$, Sérgio Setúbal ${ }^{1}$, Luiz Antonio Bastos Camacho², \\ Rita de Cássia Nasser Cubel Garcia ${ }^{3}$, Marilda Mendonça Siqueira ${ }^{4}$, \\ Renata Freire Alves Pereira ${ }^{5}$, Solange Artimos de Oliveira ${ }^{1}$
}

\footnotetext{
${ }^{1}$ Disciplina de Doenças Infecciosas e Parasitárias, Hospital Universitário Antônio Pedro ${ }^{3}$ Departamento de Microbiologia e Parasitologia, Instituto Biomédico, Universidade Federal Fluminense, Niterói, RJ, Brasil ${ }^{2}$ Departamento de Epidemiologia, Escola Nacional de Saúde Pública ${ }^{4}$ Instituto Oswaldo Cruz-Fiocruz, Rio de Janeiro, RJ, Brasil ${ }^{5}$ Escola de Farmácia, Universidade do Grande Rio, Duque de Caxias, RJ, Brasil
}

Erythrovirus B19 (B19V) infection may cause red cell aplasia in patients infected with human immunodeficiency virus (HIV). The introduction of highly active antiretroviral therapy (HAART) has improved the immune function of these patients by modifying the course of B19V infection. The purpose of this study was to estimate the frequency of B19 seroconversion in a cohort of HIV-infected patients and evaluate the occurrence of B19V-related anaemia during the seroconversion period. Adult HIV-infected patients were studied at a public hospital in Niterói, state of Rio de Janeiro, Brazil. IgG and IgM antibodies against B19V were detected by an enzyme-linked immunosorbent assay and B19 viraemia was assayed by polymerase chain reaction. Medical records were reviewed for any clinical evaluation of anaemia. Seroconversion was detected in $31.8 \%$ of the 88 individuals who began the study as antiB19V IgG-negative. No clinical manifestations of B19V infection were detected during the period of seroconversion. Patients who seroconverted were 5.40 times more likely to have anaemia than those who did not [odds ratio 5.40 (95\% confidence interval: 1.33-22.93)]. Anaemia was detected in eight patients. All patients recovered from anaemia by either beginning or continuing HAART, without requiring blood transfusions. In the HAART era, B19V infection may only be associated with a course of disease characterised by less severe chronic anaemia. This milder course of $B 19$-associated disease is likely due to the increased immune function of HAART-treated patients.

Key words: human parvovirus B19 - seroconversion - HIV infection - anaemia

Erythrovirus B19 (B19V) infection, classically linked to a common benign exanthematic disease of childhood, may cause red cell aplasia in immunocompromised patients, including those infected with human immunodeficiency virus (HIV) (Young \& Brown 2004). Anaemia is an independent predictive marker for clinical prognosis in HIV-infected patients (Mocroft et al. 1999, O'Brien et al. 2005). There are many causes of anaemia in HIVinfected patients, such as opportunistic infections and the use of antiretrovirals or antimicrobials (Abkowitz et al. 1997). Appropriate treatment for anaemia depends on the identification of the cause, for example, anaemia caused by B19V infection is treatable with high intravenous doses of human standard immunoglobulin (Frickhofen et al. 1990).

Seroprevalence studies have shown that approximately $30 \%$ of adult HIV-infected patients have no antiB19V IgG antibodies and are therefore susceptible to the infection (Gyllensten et al. 1994, van Elsacker-Neile et al. 1996, Azevedo et al. 2009). These patients remain at

Financial support: CNPq (473432/2010-2, 471618/2008-0)

+ Corresponding author: kmlazevedo@id.uff.br

Received 29 June 2011

Accepted 11 January 2012 risk for developing persistent anaemia if infected with B19V (Zuckerman et al. 1994). Epidemiological studies have shown that $\mathrm{B} 19 \mathrm{~V}$ infection occurs periodically in the form of outbreaks. These outbreaks represent an occasion in which susceptible individuals are at a higher risk of contracting B19V infection (Oliveira et al. 1996).

Prior to the highly active antiretroviral therapy (HAART) era, B19V infection in immunosuppressed HIV-infected patients manifested as persistent anaemia. The treatment for this anaemia was multiple blood transfusions and high intravenous doses of human standard immunoglobulin. The introduction of HAART into clinical practice has improved the immune function of HIVinfected individuals. This altered immune function has modified the course of B19V infection in these patients. Due to HAART, the course of B19V infection in HIVinfected patients is similar to that in immunocompetent individuals (Mylonakis et al. 1999, Arribas et al. 2000).

In the medical literature, there are only case reports about describing B19V seroconversion in HIV-positive patients and these have mostly occurred after the starting of HAART treatments (Bremner \& Cohen 1994, Arribas et al. 2000, Taguchi et al. 2001, Ware \& Moore 2001, Clarke \& Lee 2003, Watanabe et al. 2011). To better understand the importance of B19V infection in the HAART era, we conducted a study to estimate the frequency of B19V seroconversion in a cohort of HIVinfected patients. We also examined the occurrence of anaemia caused by B19V infection during the serocon- 
version period. In this generally benign viral infection, anaemia is a major clinical manifestation, particularly in immunocompromised subjects.

\section{SUBJECTS, MATERIALS AND METHODS}

Study population - Samples from a serum bank established in 2001 were used in this study. These samples were from patients who received treatment for HIV infection at the Infectious Diseases Department, Antônio Pedro University Hospital, Federal Fluminense University. This is a large tertiary public hospital in Niterói, state of Rio de Janeiro, Brazil. Niterói has approximately 441,078 inhabitants (IBGE 2010). The hospital also provides health care to other larger neighbouring municipalities and, to a lesser extent, to people from other parts of the state. A previous study had been conducted to estimate the B19V infection rate in the adult HIV-positive patients treated at the general medical outpatient care centre. The patients in that study received antiretroviral therapy and follow-up examinations to analyse $\mathrm{CD} 4^{+} \mathrm{T}$ cell counts and plasma HIV viral loads (Azevedo et al. 2009). Between November 2001-December 2003, single serum samples from 261 consecutive HIV-infected patients were tested using an enzyme immunoassay to detect anti-B19V IgG antibodies. The seroprevalence of $\mathrm{B} 19 \mathrm{~V}$ in this population was $62.8 \%$. Patients who were originally anti-B19V IgG negative and then had another serum sample collected between January 2004-July 2008 were included in the seroconversion study. The second serum sample was collected at least 12 months after the first serum sample. This study was planned to take advantage of the opportunity to detect B19V seroconversion during the B19V outbreak in Niterói that occurred from 2004-2005 (Oliveira et al. 2005).

The following definitions were used in this study: (i) the seroconversion period was defined as the time between the last negative anti-B19V IgG serum sample and the first positive anti-B19V IgG sample, (ii) anaemia was defined according to the World Health Organization criteria as a haemoglobin concentration below $13 \mathrm{~g} / \mathrm{dL}$ in men and below $12 \mathrm{~g} / \mathrm{dL}$ in women and (iii) severe anaemia was defined as a haemoglobin concentration below $7 \mathrm{~g} / \mathrm{dL}$ (WHO 2001).

Laboratory methods - Blood samples were collected and the serum samples were obtained by centrifugation of the clots. The serum samples were stored at $-20^{\circ} \mathrm{C}$. Serum samples were assigned a numerical code to conceal the identity of the study subjects. An enzyme-linked immunosorbent assay (Parvovirus B19 IgG and IgM Immunoassay; Biotrin International, Dublin, Ireland) was used to detect anti-B19V IgG and IgM antibodies in the serum samples according to the manufacturer's instructions. First, the last available serum sample for each patient was tested for anti-B19V $\operatorname{IgG}$ antibodies. If seroconversion was detected, every serum sample for that patient was examined for anti-B19V IgG antibodies to determine the seroconversion period. In addition, every serum sample that tested positive for anti-B19V IgG antibodies was also tested for anti-B19V IgM antibodies.

$\mathrm{B} 19 \mathrm{~V}$ viraemia was evaluated by the detection of B19V-specific DNA by polymerase chain reaction
(PCR) using primers that amplify a 102-bp fragment of the NS1 gene. Briefly, viral DNA was extracted from serum samples using a QIAamp DNA Blood Mini Kit (QIAGEN, Brasil) according to the manufacturer's instructions. The PCR assay was performed using 12.5 pmol of the primers E1905F (nt 1905-1923) and E1987R (nt 2007-1987) as previously described by Nguyen et al. (2002) with some modifications. After an initial denaturation step at $94^{\circ} \mathrm{C}$ for $10 \mathrm{~min}$, amplification consisted of 35 cycles of incubations at $94^{\circ} \mathrm{C}$ for $30 \mathrm{~s}, 55^{\circ} \mathrm{C}$ for $30 \mathrm{~s}$ and $72^{\circ} \mathrm{C}$ for $30 \mathrm{~s}$, followed by a final extension of $7 \mathrm{~min}$ at $72^{\circ} \mathrm{C}$. The 102 -bp PCR products were resolved on $1 \%$ agarose gel followed by ethidium bromide staining and the amplified DNA was visualised under ultraviolet light. Distilled milli-Q water was used as a negative control in all techniques and the recommended manipulations for the PCR procedures were performed as a precaution to avoid false-positive results.

PCR was conducted on the last serum sample that tested negative for anti-B19V IgG antibodies and on the first serum sample that was anti-B19V IgG positive in all cases of seroconversion. Then, for the cases with no documented seroconversion, a PCR viraemia test was performed on the last serum sample. If the PCR assay was positive for B19V viral DNA, all subsequent samples in the serum bank were tested to determine the duration of B19V viraemia.

Data analysis - Data were entered and analysed using the SPSS 17.0 software (Statistical Package for Social Sciences, Inc, Chicago, IL, USA). Continuous variables were categorised. Differences in proportions were assessed using the chi-squared test. Odds ratios (OR) and their 95\% confidence intervals (CI) were calculated to measure the association between anti-B19V IgG antibody conversion and risk factors, including demographic characteristics, $\mathrm{CD}^{+} \mathrm{T}$ cell counts, HIV viral load and haemoglobin level. Multivariate analysis (logistic regression) was used to adjust for the effect of covariates with substantial association in the univariate analysis. A $5 \%$ significance level was adopted for all results.

Ethics - Written informed consent was obtained from all volunteers and the project was approved by the Hospital Review Board (CMM/HUAP 134/05).

\section{RESULTS}

Eighty-eight patients who tested negative for antiB19V IgG antibodies were included in this study. There were $46(52.3 \%)$ women (mean age: 38.6 years) and 42 (47.7\%) men (mean age: 42.0 years). The interval between the last negative and the first positive serum sample (seroconversion period) varied from two-18 months (mean: 8.1 months; median: 7.0 months).

Seroconversion to anti-B19V IgG antibodies was detected in $28(31.8 \%)$ of the patients, but anti-B19V IgM antibodies were present in only three of the patients who seroconverted. Seroconversion was more frequent in serum samples that were collected in $2005(9 / 28 ; 32.1 \%)$ and $2006(6 / 28 ; 21.4 \%)$ than in those collected in 2007 and 2008. No clinical manifestations of B19V infection were detected in the medical records of these patients during the seroconversion period. The differences in 
B19V seroconversion across sex, age and educational categories were neither substantial nor statistically significant. CD4 ${ }^{+} \mathrm{T}$ cell counts and HIV viral load did not appear to be associated with anti-B19V IgG seroconversion. Patients who had seroconverted were found to be 5.40 (95\% CI 1.33-22.93) times more likely to have anaemia in the last negative serum sample compared to those who did not seroconvert (Table); however, this increase in anaemia incidence was not found to be statistically significant in the first serum sample that tested positive for anti-B19V IgG antibodies.

During the period of seroconversion, transient anaemia was present in one patient and lasted for three months. Chronic anaemia, which refers to anaemia that persists longer than five months, was observed in seven patients, but only one of them presented with severe anaemia (haemoglobin: $5.9 \mathrm{~g} / \mathrm{dL}$ ). Anaemia was also detected in two additional patients, but there were no sequential samples available to characterise its duration. Out of the 28 patients who seroconverted, 13 had no anaemia during the seroconversion period. In the remaining five cases, there were no data in the medical records regarding the occurrence of anaemia. All patients had recovered from anaemia by either beginning or continuing HAART and none of them required immunoglobulins or blood transfusions.

The use of zidovudine was the main variable found to be correlated with anaemia. Zidovudine was used in 37 of the 88 cases in this study. However, although there was a strong association between the occurrence of anaemia and the use of this medication, it was not a statistically significant association (OR: $2.58 ; 95 \% \mathrm{CI}$ : 0.67-9.96; $p=0.169$ ) (data not shown).

$\mathrm{B} 19 \mathrm{~V}$ viraemia, as measured by the detection of B19V DNA with PCR in the serum samples, was found in four of the 28 patients who had seroconverted. In two cases, viraemia was detected in only one serum sample, whereas in the remaining two cases, viraemia was detected in a sequential serum sample that was collected three months later in one patient and nine months later in the other patient. Anaemia was identified in two of those four patients during the seroconversion period, but only one patient had severe chronic anaemia. The other two cases lacked any data regarding anaemia incidence in the medical records during that period. Viraemia was not detected in the last set of serum samples of the 60 patients who had not seroconverted.

\section{DISCUSSION}

To our knowledge, this is the largest study to date that has examined B19V seroconversion in HIV-infected patients. In the medical literature, there are only reports of isolated cases, primarily after patients had begun HAART treatment (Bremner \& Cohen 1994, Arribas et al. 2000, Taguchi et al. 2001, Ware \& Moore 2001, Clarke \& Lee 2003). The high rate of $\mathrm{B} 19 \mathrm{~V}$ seroconversion in the present study [28 (31.8\%) out of 88 individuals] may be explained by the wide exposure of the population to this virus during the epidemic. Epidemiological studies have shown that $\mathrm{B} 19 \mathrm{~V}$ infection increases periodically. Oliveira et al. (2003) identified a seasonal pattern of B19V infection by systematically gathering data on acute rash diseases over six years. During the study period, three distinct peaks of parvovirus infection were detected, suggesting that the disease appears to cycle in approximately four-five years. Another study identified an outbreak in Niterói, in 20042005 (Oliveira et al. 2005). In the current study, B19V seroconversion was detected in nine patients in 2005 and in six patients in 2006 ( 32.1 and $21.4 \%$, respectively), but it is possible that three of the cases in 2006 may have actually occurred in 2005. Due to the long intervals between the serum samples from these patients, the exact seroconversion period could not be ascertained.

B19V infections are generally acute and self-limiting. However, persistent infections have been demonstrated in immunocompetent individuals by the detection of B19V DNA in blood or bone marrow samples that were collected years after infection. The mechanisms of B19V persistence are not known (Cassinotti \& Siegl 2000). Reactivation of persistent infection occurs in immunocompetent and, more often, in immunocompromised individuals (Cassinotti et al. 1997). Theoretically, it is possible that in HIV-infected individuals with severe immunodeficiency, the reactivation of persistent infection occurs more frequently.

The main receptor for $\mathrm{B} 19 \mathrm{~V}$ is globoside $\mathrm{P}$, which is present on erythroid cells. The viral replication in these cells causes destruction of the erythroid progenitors, resulting in a disruption of erythropoiesis and anaemia (Young \& Brown 2004). Immunosuppressed patients are at risk of developing acute or chronic anaemia following B19V infection due to a lack of protective antibodies. Life-threatening anaemia can develop due to the inability of these patients to mount an immune response to clear the viraemia. In HIV-infected patients, severe immunodeficiency may cause an impairment of the immune response to $\mathrm{B} 19 \mathrm{~V}$, leading to persistent viraemia and chronic anaemia (Abkowitz et al. 1997, Setúbal et al. 2003). The strong association of anaemia with B19V infection provides a relevant parameter for the clinical assessment of HIV-infected patients, particularly in periods of $\mathrm{B} 19 \mathrm{~V}$ outbreaks.

Anaemia is the most common haematologic abnormality observed in HIV-infected patients (Koduri 2000). There are many causes of anaemia in these patients, including the following: co-infection with mycobacteria, fungus, cytomegalovirus and B19V. Drugs, such as zidovudine, trimethoprim sulfamethoxazole and antineoplastic drugs have also been shown to cause anaemia in HIV-infected patients. Finally, lymphoma and the direct effect of HIV on the function of accessory cells within the bone marrow microenvironment can also cause anaemia (Abkowitz et al. 1997).

Patients who had seroconverted were 2.6 times more likely to develop anaemia (Table), which is similar to the value found by Calvet et al. (1999) in organ transplant recipients. In the present study, the lack of a significant association between anaemia and predisposing factors other than $\mathrm{B} 19 \mathrm{~V}$ seroconversion reinforces the importance of the role of $\mathrm{B} 19 \mathrm{~V}$ infection as a cause of anaemia in HIV-infected patients, particularly during periods of high viral activity. 


\section{TABLE}

Erythrovirus B19 (B19V)-IgG seroconversion among human immunodeficiency virus (HIV) infected-patients, according to demographic, clinical and laboratory parameters, Niterói, state of Rio de Janeiro, 2001-2008

\begin{tabular}{|c|c|c|c|c|}
\hline \multirow[b]{2}{*}{ Characteristic } & \multicolumn{2}{|c|}{$\begin{array}{c}\text { Seroconversion IgG B19V } \\
\text { antibodies }\end{array}$} & \multirow[b]{2}{*}{$\mathrm{p}$} & \multirow[b]{2}{*}{$\begin{array}{c}\mathrm{OR} \\
(95 \% \mathrm{CI})\end{array}$} \\
\hline & $\begin{array}{c}\text { Yes } \\
\mathrm{n}(\%)\end{array}$ & $\begin{array}{c}\text { No } \\
\mathrm{n}(\%)\end{array}$ & & \\
\hline Gender & & & $0.950^{a}$ & \\
\hline Male & $13(31)$ & $29(69)$ & - & $\begin{array}{c}0.93 \\
(0.34-2.50)\end{array}$ \\
\hline Female & $15(32.6)$ & $31(67.4)$ & - & 1.0 \\
\hline Age groups (years) & & & $0.082^{a}$ & \\
\hline$<40$ & $12(29.3)$ & $29(70.7)$ & - & $\begin{array}{c}0.80 \\
(0.29-2.17)\end{array}$ \\
\hline$\geq 40$ & $16(34)$ & $31(66)$ & - & 1.0 \\
\hline Educational level & & & $0.911^{a}$ & \\
\hline Elementary & $13(34.2)$ & $25(65.8)$ & - & $\begin{array}{c}0.91 \\
(0.27-3.14)\end{array}$ \\
\hline High school and college & $8(36.4)$ & $14(63.6)$ & - & 1.0 \\
\hline Unknown & $7(25)$ & $21(75)$ & - & - \\
\hline Clinical characteristics & & & $0.522^{b}$ & \\
\hline Asymptomatic & $4(28.6)$ & $10(71.4)$ & - & $\begin{array}{c}0.83 \\
(0.20-3.32)\end{array}$ \\
\hline Acquired immune deficiency syndrome & $24(32.4)$ & $50(67.6)$ & - & 1.0 \\
\hline $\mathrm{CD}^{+}$cell count $/ \mathrm{mm}^{3}$ in the last serum sample B19V-IgG-negative & & & $0.350^{a}$ & \\
\hline$\leq 200$ & $8(44.4)$ & $10(55.6)$ & - & $\begin{array}{c}1.94 \\
(0.58-6.43)\end{array}$ \\
\hline$>200$ & $19(29.2)$ & $46(70.8)$ & - & 1.0 \\
\hline Unknown & $1(20)$ & $4(80)$ & - & - \\
\hline $\mathrm{CD}^{+}$cell count $/ \mathrm{mm}^{3}$ in the first serum sample B19V-IgG-positive & & & $0.694^{a}$ & \\
\hline$\leq 200$ & $5(41.7)$ & $7(58.3)$ & - & $\begin{array}{c}1.58 \\
(0.38-6.40)\end{array}$ \\
\hline$>200$ & $23(31.1)$ & $51(68.9)$ & - & 1.0 \\
\hline Unknown & $0(0)$ & $2(100)$ & - & - \\
\hline Plasma HIV load (copies/mL) in the last serum sample B19V-IgG-negative & & & $0.861^{a}$ & \\
\hline$<1.000$ & $15(31.2)$ & $33(68.8)$ & - & $\begin{array}{c}0.96 \\
(0.32-2.94)\end{array}$ \\
\hline$\geq 1.000$ & $9(32.1)$ & $19(67.9)$ & - & 1.0 \\
\hline Unknown & $4(33.3)$ & $8(66.7)$ & - & - \\
\hline Plasma HIV load (copies/mL) in the first serum sample B19V-IgG-positive & & & $0.903^{a}$ & \\
\hline$<1.000$ & $15(31.3)$ & $33(68.7)$ & - & $\begin{array}{c}1.23 \\
(0.38-4.07)\end{array}$ \\
\hline$\geq 1.000$ & $7(26.9)$ & $19(73.1)$ & - & 1.0 \\
\hline Unknown & $6(42.9)$ & $8(57.1)$ & - & - \\
\hline Haemoglobin in the last serum sample B19V-IgG-negative & & & $0.008^{a}$ & \\
\hline Anaemia & $9(60)$ & $6(40)$ & - & $\begin{array}{c}5.40 \\
(1.33-22.93)\end{array}$ \\
\hline No anaemia & $10(21.7)$ & $36(78.3)$ & - & 1.0 \\
\hline Unknown & $9(33.3)$ & $18(66.7)$ & - & - \\
\hline Haemoglobin in the first serum sample B19V-IgG-positive & & & $0.132^{b}$ & \\
\hline Anaemia & $6(50)$ & $6(50)$ & - & $\begin{array}{c}2,57 \\
(0,60-11,21)\end{array}$ \\
\hline No anaemia & $14(28)$ & $36(72)$ & - & 1.0 \\
\hline Unknown & $8(30.8)$ & $18(69.2)$ & - & - \\
\hline
\end{tabular}

$a$ : Pearson chi-square test; $b$ : Fisher exact test; CI: confidence interval; OR: odds ratio. 
$\mathrm{B} 19 \mathrm{~V}$ seroconversion was detected more frequently in patients whose $\mathrm{CD} 4^{+} \mathrm{T}$ cell counts were below 200 cells/ $\mathrm{mm}^{3}$, but this study lacked sufficient statistical power to make an unequivocal conclusion regarding this finding. It is possible that the use of HAART has contributed to a better immune response to $\mathrm{B} 19 \mathrm{~V}$ infection, even before a detectable increase in the number of $\mathrm{CD} 4^{+} \mathrm{T}$ cells in the blood is found. This is consistent with the known impact of restoring the immune response through the initiation of HAART, which could reduce or even eliminate the severe haematological changes caused by B19V infection (Arribas et al. 2000, Scapellato \& Palumbo 2000, Ware \& Moore 2001). These facts may explain the low frequency of severe anaemia observed in our study: only one out of seven patients had chronic anaemia during the seroconversion period.

Raguin et al. (1997) determined the prevalence of B19V in 55 HIV-infected patients. Anti-B19V IgG antibodies were detected in 53/55 (96\%) of the serum samples and anti-B19V IgM antibodies were detected in only five $(10 \%)$ patients who were also positive for anti-B19V IgG antibodies. Viral DNA was not detected in any of the 55 serum samples by PCR in that study. The prevalence of IgM-positive sera $(10 \%-5 / 53$ patients) in that previous study was similar to that observed in our study $(10.7 \%$ - 3/28 patients). However, Calvet et al. (1999) detected anti-B19V IgM antibodies in 12/24 (50\%) patients who tested positive for B19V in a group of 62 transplanted patients. Compared with the results of the current study, the high proportion of IgM detected in that study may be associated with the shorter interval of collection and testing of serum samples by those authors.

The immune response may be altered by immunosuppression; consequently, genome detection has been largely applied in this clinical context (Kurtzman et al. 1989, Calvet et al. 1999). Calvet et al. (1999) found a frequent dissociation between the molecular and serological markers of B19V infection in transplant patients; 60/109 PCR-positive specimens showed no evidence of recent infection and only two of the 24 patients with B19V infection had more than $40 \%$ of their samples test positive by either serology or PCR. In our study, viraemia was detected in a single serum sample in two/four patients who seroconverted (1 patient seroconverted in 2005 and the other in 2006). In the other two patients, two sequential serum samples were positive for B19V DNA. Of these two patients, both had seroconverted in 2005. One patient had a PCR-positive sample three months after the previous PCR-positive sample and the other patient had a PCRpositive sample nine months later in 2006. Although some studies (Naides et al. 1993, Abkowitz et al. 1997) have suggested the possibility of the persistence of B19V viraemia in HIV-infected patients, other authors demonstrated that this is unusual even among these immunocompromised individuals (Bremner \& Cohen 1994, Raguin et al. 1997). In patients who are persistently positive for B19V DNA, acute or chronic clinical features may not be present when the levels of viraemia are low (Musiani et al. 1995b). In this study, the presence of B19V DNA was detected by PCR, which can detect low levels of viraemia for several months after the initial infection (Musiani et al. 1995a).
This study had limitations that are inherent a retrospective study that involves a review of medical record. One of the main limitations is the long intervals between blood collections. These long periods made it difficult to more precisely define the time of $\mathrm{B} 19 \mathrm{~V}$ seroconversion, especially for the evaluation of anaemia. However, these blood tests were performed because they were deemed necessary based on the physicians' clinical assessments of these patients. Considering that only one case of severe anaemia was observed during the seroconversion period, it is plausible to assume that even if anaemia had been identified through laboratory tests, it would most likely not have been of great magnitude. There were no reports in the medical records of complaints or changes found during the physical examinations that would be consistent with the presence of severe anaemia.

In conclusion, our findings show that in the HAART era, B19V infection may be restricted, subtle and only apparent in retrospective analyses. The presence of chronic anaemia, especially during B19V epidemics, should alert the physician to the possibility of B19V infection. Because this is a treatable cause of anaemia, identification of $\mathrm{B} 19 \mathrm{~V}$ infection could reduce the risk of multiple blood transfusions and other unnecessary therapeutic measures. Detection of DNA-B19V by PCR may indicate viraemia; however, our results suggest that viraemia is not necessarily associated with clinical manifestations of B19V infection.

\section{REFERENCES}

Abkowitz JL, Brown KE, Wood RW, Kovach NL, Green SW, Young NS 1997. Clinical relevance of parvovirus B19 as a cause of anaemia in patients with human immunodeficiency virus infection. J Infect Dis 176: 269-273.

Arribas JR, Peña JM, Echevarría JE 2000. Parvovirus B19-related anaemia in an HIV-infected patient: rapid control after production of neutralizing antibodies during highly active antiretroviral therapy. Ann Intern Med 132: 1011.

Azevedo KML, Setúbal S, Camacho LAB, Velarde LGC, Oliveira SA 2009. Seroepidemiological study of human parvovirus B19 among human immunodeficiency virus-infected patients in a medium-sized city in Rio de Janeiro, Brazil. Mem Inst Oswaldo Cruz 104: 901-904.

Bremner JAG, Cohen BJ 1994. Parvovirus B19 as a cause of anaemia in human immunodeficiency virus-infected patients [letter]. $J$ Infect Dis 169: 938-939.

Calvet A, Pujol MO, Bertocchi M, Basgien O, Boissonnat P, Mornex JF 1999. Parvovirus B19 infection in thoracic organ transplant recipients. J Clin Virol 13: 37-42.

Cassinotti P, Burtonboy G, Foppe M, Siegl G 1997. Evidence for persistence of human parvovirus B19 DNA in bone marrow. $J$ Med Virol 53: 229.

Cassinotti P, Siegl E 2000. Quantitative evidence for persistence of human parvovirus B19 DNA in an immunocompetent individual. Eur J Clin Microbiol Infect Dis 19: 886-895.

Clarke J, Lee JD 2003. Primary human parvovirus B19 infection in an HIV infected patient on highly active antiretroviral therapy. Sex Transm Infect 79: 336.

Frickhofen N, Abkowitz JS, Safford M, Berry JM, Antunez-de-Mayolo J, Astrow A 1990. Persistent B19 parvovirus infection in patients infected with human immunodeficiency virus type 1 (HIV-1): a treatable cause of anaemia in AIDS. Ann Intern Med 113: 926-933. 
Gyllensten K, Sönnerborg A, Jorup-Rönström C, Halvarsson M, Yun Z 1994. Parvovirus B19 infection in HIV-1 infected patients with anaemia. Infection 22: 356-358.

IBGE - Instituto Brasileiro de Geografia e Estatística 2010. Census Data [Dados do Censo 2010]. Available from: censo2010.ibge. gov.br/dados_divulgados/index.php?uf=33.

Koduri 2000. Parvovirus B19-related anaemia in HIV-infected patients. AIDS Patient Care STDS 14: 7-11.

Kurtzman GL, Cohen BJ, Field AM, Oseas R, Blaese RM, Young NS 1989. Immune response to B19 parvovirus and an antibody defect in persistent viral infection. J Clin Invest 84: 1114-1123.

Mocroft A, Kirk O, Bartin SE, Dietrich M, Proença R, Colebunders R 1999. Anaemia is an independent predictive marker for clinical prognosis in HIV-infected patients from across Europe. AIDS 13: 943-950.

Musiani M, Zerbini M, Gentilomi G, Plazzi M, Gallinella G, Venturoli S 1995a. Parvovirus B19 clearance from peripheral blood after acute infection. J Infect Dis 172: 1360-1363.

Musiani M, Zerbini M, Gentilomi G, Rodrigo G, de Rosa V, Gibellini D, Venturoli S, Gallinella G 1995b. Persistent B19 parvovirus infections in haemophilic HIV-1 infected patients. $J$ Med Virol 46: 103-108.

Mylonakis E, Dickinson BP, Mileno MD, Flanigan T, Schiffman FJ, Mega A 1999. Persistent parvovirus B19 related anaemia of seven years' duration in an HIV-infected patient: complete remission associated with highly active antiretroviral therapy. Am J Hematol 60: 164-166.

Naides SJ, Howard EJ, Swack NS, True CA, Stapleton JT 1993. Parvovirus B19 infection in human immunodeficiency virus type 1-infected persons failing or intolerant to zidovudine therapy. J Infect Dis 168: 101-105.

Nguyen QT, Wong S, Heegaard ED, Brown KE 2002. Identification and characterization of a second novel human erythrovirus variant A6. Virology 301: 374-380.

O’Brien ME, Kupka R, Msamanga GI, Saathoff E, Huntern DJ, Fawzi WW 2005. Anaemia is an independent predictor of mortality and immunologic progression of disease among women with HIV in Tanzania. J Acquir Immune Defic Syndr 40: 219-225.

Oliveira SA, Brandão AB, Fernandes DG, Bettini LR, Carvalho AB, Pereira ACM 1996. Human parvovirus B19 infection: clinical and epidemiological study of 24 cases. Rev Inst Med Trop Sao Paulo 38: 323-327.
Oliveira SA, Camacho LAB, Pereira ACM, Faillace TF, Setúbal S, do Nascimento JP 2003. Clinical and epidemiological aspects of human parvovirus B19 infection in an urban area in Brazil (Niterói city area, state of Rio de Janeiro, Brazil). Mem Inst Oswaldo Cruz 97: 965-970.

Oliveira SA, Marinho TAS, Silva ASV, Rodrigues NB, Faria RA, Setúbal S 2005. Estudo da frequência da infecção pelo parvovírus B19 em casos de doenças exantemáticas no período de 1994 a 2004. Braz J Infect Dis 9 (Suppl.): 73.

Raguin G, Leruez-Ville M, Gregoire V, Deplanche M, Leport C, Morinet $\mathrm{F}$ 1997. Low prevalence of active parvovirus B19 infection in HIV-infected patients. Eur J Clin Microbiol Infect Dis 16: 760-762.

Scapellato PG, Palumbo AM 2000. Improvement of anaemia induced by parvovirus B19 in a patient with AIDS after combined antiretroviral therapy [letter]. Mayo Clin Proc 75: 215-217.

Setúbal S, Jorge-Pereira MC, Sant'Anna ALM, Oliveira AS, Bazin AR, Nascimento JP 2003. Clinical presentation of parvovirus B19 infection in HIV-infected patients with and without AIDS. Rev Soc Bras Med Trop 36: 299-302.

Taguchi H, Takahashi T, Goto M, Nakamura T, Iwamoto A 2001. Acute parvovirus B19 infection during anti-retroviral therapy. J Infect Chemother 7: 110-112.

van Elsacker-Neile AM, Kroon FP, van der Ende ME, Salimans MM, Spaan WJ, Kroes AC 1996. Prevalence of parvovirus B19 infection in patients infected with human immunodeficiency virus. Clin Infect Dis 23: 1255-1260.

Ware AJ, Moore T 2001. Resolution of chronic parvovirus B19induced anaemia by use of highly active antiretroviral therapy in a patient with acquired immunodeficiency syndrome. Clin Infect Dis 32: e122-123.

Watanabe D, Taniguchi T, Otani N, Tominari S, Nishida Y, Uehira T, Shirasaka T 2011. Immune reconstitution to parvovirus B19 and resolution of anaemia in a patient treated with highly active antiretroviral therapy. J Infect Chemother 17: 283-287.

WHO - World Health Organization 2001. Iron deficiency anaemia. Assessment, prevention and control, WHO, Geneva, p. 33-46.

Young NS, Brown KE 2004. Mechanisms of disease Parvovirus B19. N Engl J Med 350: 586-597.

Zuckerman MA, Williams I, Bremmer J, Cohen B, Miller RF 1994. Persistent anaemia in HIV-infected individuals due to parvovirus B19 infection. AIDS 8: 1191-1192. 